\title{
Overt hepatic encephalopathy in Italy: clinical outcomes and healthcare costs
}

This article was published in the following Dove Press journal:

Hepatic Medicine: Evidence and Research

13 July 2015

Number of times this article has been viewed

\author{
Daniela Paola Roggeri' \\ Alessandro Roggeri' \\ Elisa Rossi ${ }^{2}$ \\ Elisa Cinconze ${ }^{2}$ \\ Antonio Gasbarrini ${ }^{3}$ \\ PierAlessandro Monici Preti ${ }^{4}$ \\ Marisa De Rosa ${ }^{2}$ \\ 'ProCure Solutions, Nembro, \\ Bergamo, ${ }^{2} \mathrm{CINECA}$, Interuniversity \\ Consortium, Bologna, ${ }^{3}$ Catholic \\ University of Sacred Heart, Policlinic \\ A Gemelli, Rome, ${ }^{4}$ Alfa Wassermann, \\ Bologna, Italy
}

Purpose: Hepatic encephalopathy (HE) is a recurrent severe complication of progressive hepatic cirrhosis. The aim of this study is to evaluate the average annual direct healthcare costs for the treatment of patients with overt HE in Italy.

Patients and methods: This retrospective, observational study analyzed information from the database of ARNO Observatory. Patients with at least one hospitalization due to overt HE in the period from January 1, 2011 to December 31, 2011, were selected and observed during the year following the hospitalization. Costs for drugs, diagnostic and therapeutic procedures, and hospitalizations were estimated from the Italian National Health Service perspective.

Results: Out of a population of 2,678,462 subjects, 381 patients were identified, of whom, $21.5 \%$ died during the first hospitalization and 5.8\% during the follow-up; the survival rate was $72.7 \%$ at the end of the observation period. The direct healthcare costs per patient amounted to $€ 13,393 /$ year ( 15,295 USD) ( $88 \%$ for hospitalizations, $8 \%$ for drugs, and $4 \%$ for diagnostic procedures). During the follow-up, $42.5 \%$ of patients had at least one rehospitalization due to HE. Patients readmitted for HE had an average annual cost of $€ 21,272$ (24,293 USD), almost doubled if compared to patients without readmissions (€12,098 [13,816 USD]).

Conclusion: This analysis showed that patients with HE had relevant direct healthcare costs, in which hospitalizations were the most important cost drivers.

Keywords: hepatic encephalopathy, costs, hospitalizations, relapses

\section{Introduction}

Hepatic encephalopathy (HE), as defined by the European Association for the Study of the Liver (EASL) clinical practice guidelines, ${ }^{1}$ is a brain dysfunction caused by liver insufficiency and/or portosystemic shunting; it manifests as a wide spectrum of neurological or psychiatric abnormalities ranging from subclinical alterations to coma. Alterations in patient consciousness, intellect, personality, and neuromuscular activity can be considered as the most important manifestations of episodes of overt $\mathrm{HE} .^{2} \mathrm{HE}$ deeply affects hospitalization rates and the quality of life of patients and caregivers, both physically and mentally. ${ }^{3-7}$ The direct costs associated with liver diseases are extremely relevant. ${ }^{8}$ The American Gastroenterological Association, using data from the 1995 National Health Interview Survey and adjusting them to 1998, estimates that the annual economic burden of chronic liver disease, cirrhosis, and hepatitis $\mathrm{C}$ is over $\$ 2.1$ billion and the indirect costs is $>\$ 272$ million. ${ }^{9}$ Hospitalizations represented the major cost driver in patients with advanced liver diseases, with an annual expenditure exceeding \$1.4 billion. The most relevant studies regarding resource consumption of patients with HE, conducted in the US, found out that HE has a relevant and increasing
Correspondence: Alessandro Rogger ProCure Solutions, Via Camozzi I/c 24027 Nembro, Bergamo, Italy Tel +39035521121

Email alessandro.roggeri@

procuresolutions.it 
economic burden. ${ }^{10,11}$ The analysis of hospital discharges with principal diagnosis of HE in 2004 (HE or unspecified encephalopathy), in particular, revealed a $180 \%$ increase since $1993 .^{10}$

To our knowledge, there are no economic data regarding patients suffering from HE in European countries, particularly in Italy. Our objective, in line with the suggestion of EASL, was to estimate direct healthcare costs and resource consumption, with particular focus on hospitalizations, for patients with overt HE in Italy.

\section{Materials and methods}

In Italy, citizens have access to the healthcare services provided by the Italian National Health Service (INHS). Information on all healthcare interventions covered by the INHS is collected in local/regional databases. For the purpose of the present study, CINECA Interuniversity Consortium provided data from the ARNO observatory. ${ }^{12}$ The ARNO observatory is an online, multicenter, observational database collecting population-based healthcare-related data (from several local health units across Italy), in which for each patient the data were combined and aggregated through epidemiological methods. These data include territorial drugs prescriptions, hospitalizations, diagnostic laboratory tests, and therapeutic procedures. This information is linked to other sources of patient data (including vital statistics and patient demographics) in order to construct a tool that is useful to provide comprehensive tracking of clinical diagnoses and healthcare use trends throughout Italy. In the present study, we analyzed data starting from a population of 2,678,462 subjects, of whom $47.3 \%$ came from northern regions, $31 \%$ from central regions, and $21.7 \%$ from southern regions of the country.

This was a retrospective, observational, and noninterventional study, for which all patients undergoing at least one hospitalization due to HE in the period of January 1, 2011, to December 31, 2011, were selected and observed for a period of 12 months following the hospitalization. As data reported in the ARNO observatory database were analyzed anonymously, ethical consent was not required.

Index hospitalizations for HE were identified through the International Classification of Diseases, Ninth Revision, Clinical Modification (ICD9-CM) code 572.2 (hepatic coma: HE, portal-systemic encephalopathy, hepatocerebral intoxication); ${ }^{13}$ hospitalizations related to $\mathrm{HE}$ relapses occurred during the observational period were identified through the following ICD9-CM codes: 572.2 (hepatic coma: HE, portal-systemic encephalopathy, hepatocerebral intoxication), 572.4 (hepatorenal syndrome), and 39.1 (transjugular intrahepatic portosystemic shunts - TIPS). Abovementioned ICD9-CM codes were reported in the hospital discharge records available for all patients.

Comorbidities were summarized by the Charlson index. ${ }^{14}$

The following resource consumptions were evaluated: drugs reimbursed by INHS (public prices reimbursed by INHS), diagnostic and therapeutic procedures (Italian national tariffs), and inpatient admissions and day hospitals (Italian national tariffs for the supply of hospital care). As only direct healthcare resources in charge to INHS were considered, the perspective of the analysis was that of INHS. Costs are expressed both in Euros and in US Dollars with an exchange rate of $€ 1.00=1.1420$ USD.

\section{Statistical analysis}

A nonparametric statistical hypothesis test (WilcoxonMann-Whitney) was used to compare the average yearly costs for female and male HE populations and to compare patients with and without rehospitalization. Another nonparametric test (Kruskal-Wallis) was used to compare the average yearly costs for the different age classes of patients. All statistical analyses were conducted using $\mathrm{R}$ software version 3.1 , with $5 \%$ of significance level.

\section{Results}

Out of a total analyzed population of 2,678,462 subjects, 381 patients were hospitalized for an overt HE episode ( $0.014 \%$ of the observed population). The selected cohort of patients had a mean age of $68 \pm 13$ (mean \pm SD) years, $34.4 \%$ were females with a mean age of $72 \pm 13$ years. The mean age of males was $66 \pm 13$. More than $52 \%$ of patients were older than 70 years. The Charlson index calculated by age classes highlights the high severity level of the population analyzed, irrespective of age class (Table 1).

Out of 381 patients with overt HE, $82(21.5 \%)$ died during the index hospitalization and $22(5.8 \%)$ died in hospital during the 1-year follow-up, with a mean time to death of

Table I Average Charlson index by age classes

\begin{tabular}{lll}
\hline Age class $(\mathbf{y r})$ & Average Charlson index & SD \\
\hline$<39$ & 8.4 & 4.3 \\
$40-49$ & 8.6 & 4.7 \\
$50-59$ & 9.2 & 5.2 \\
$60-69$ & 9.2 & 3.6 \\
$70-79$ & 9.5 & 4.4 \\
$\geq 80$ & 8.0 & 3.1 \\
\hline
\end{tabular}

Abbreviations: $y r$, year; SD, standard deviation. 
$31 \pm 24$ days. The survival rate in the full observation period was $72.7 \%$.

Among those patients who were discharged alive from hospital at the index event, $42.5 \%$ (28.4\% females) had at least one rehospitalization due to HE during the follow-up and $57.5 \%$ (39.5\% females) did not exhibit recurrences. The mean time to event for patients with at least one recurrence was $96 \pm 94$ days. In detail, time to event was $95 \pm 93$ days for patients exhibiting a recurrence of HE, $113 \pm 103$ days for patients with a relapse of hepatorenal syndrome, and $239 \pm 57$ days for patients undergoing TIPS. About $92.9 \%$ of hospitalized patients had a recurrence of $\mathrm{HE}, 15.7 \%$ had a recurrence of hepatorenal syndrome, and $1.6 \%$ of them underwent TIPS.

The mean direct healthcare costs of a single relapse requiring hospital admission for HE was $€ 3,361 \pm 1,286$ ( 3,838 USD $\pm 1,469)$, for hepatorenal syndrome was $€ 3,242 \pm 1,382$ ( 3,702 USD $\pm 1,578)$, and for TIPS was $€ 17,679 \pm 6,627(20,189$ USD $\pm 7,568$ ).

The mean length of stay for each single hospitalization was $9 \pm 7$ days for HE, $12 \pm 9$ days for hepatorenal syndrome, and $21 \pm 15$ days for TIPS.

The average yearly cost for each of the 381 selected patients was $€ 13,393 \pm 19,184$ (15,295 USD $\pm 21,908)$, of which $€ 11,791 \pm 18,134$ (13,465 USD $\pm 20,709)$ (88\%) were spent for ordinary hospitalizations and day hospitals, $€ 1,075 \pm 1,728(1,228$ USD $\pm 1,973)(8 \%)$ for drugs, and $€ 527 \pm 1,268$ (602 USD $\pm 1,448$ ) (4\%) for diagnostic and therapeutic procedures. Costs were higher for males than for females $(€ 13,989 \pm 16,459[15,975$ USD $\pm 18,796]$ vs $€ 12,246$ $\pm 24,227[13,985 \mathrm{USD} \pm 27,667] ; P=0.081)$. The average cost per patient significantly decreased with the increasing of age (from $€ 32,291$ [36,876 USD] in patients $<39$ years old to $€ 8,025$ [9,165 USD] in patients $>80$ years old; $P=0.035$ ) (Figure 1). The huge expenditure differences among age classes could be explained by the fact that liver transplantation was performed only in younger patients (hospitalizations for liver transplantation has a unitary cost of about $€ 80,200$ [91,588 USD]) and not performed in elderly.

Patients with at least one rehospitalization for HE had on average a nearly double annual cost of $€ 21,272$ (24,293 USD) compared to that of patients without relapses $(€ 12,098$ $[13,816 \mathrm{USD}])(P<0.001)$. Cost components are summarized in Table 2. Patients undergoing TIPS had an average yearly cost of $€ 36,471$ (41,650 USD).

The most frequent causes of ordinary hospitalizations during the follow-up were mainly related to liver diseases

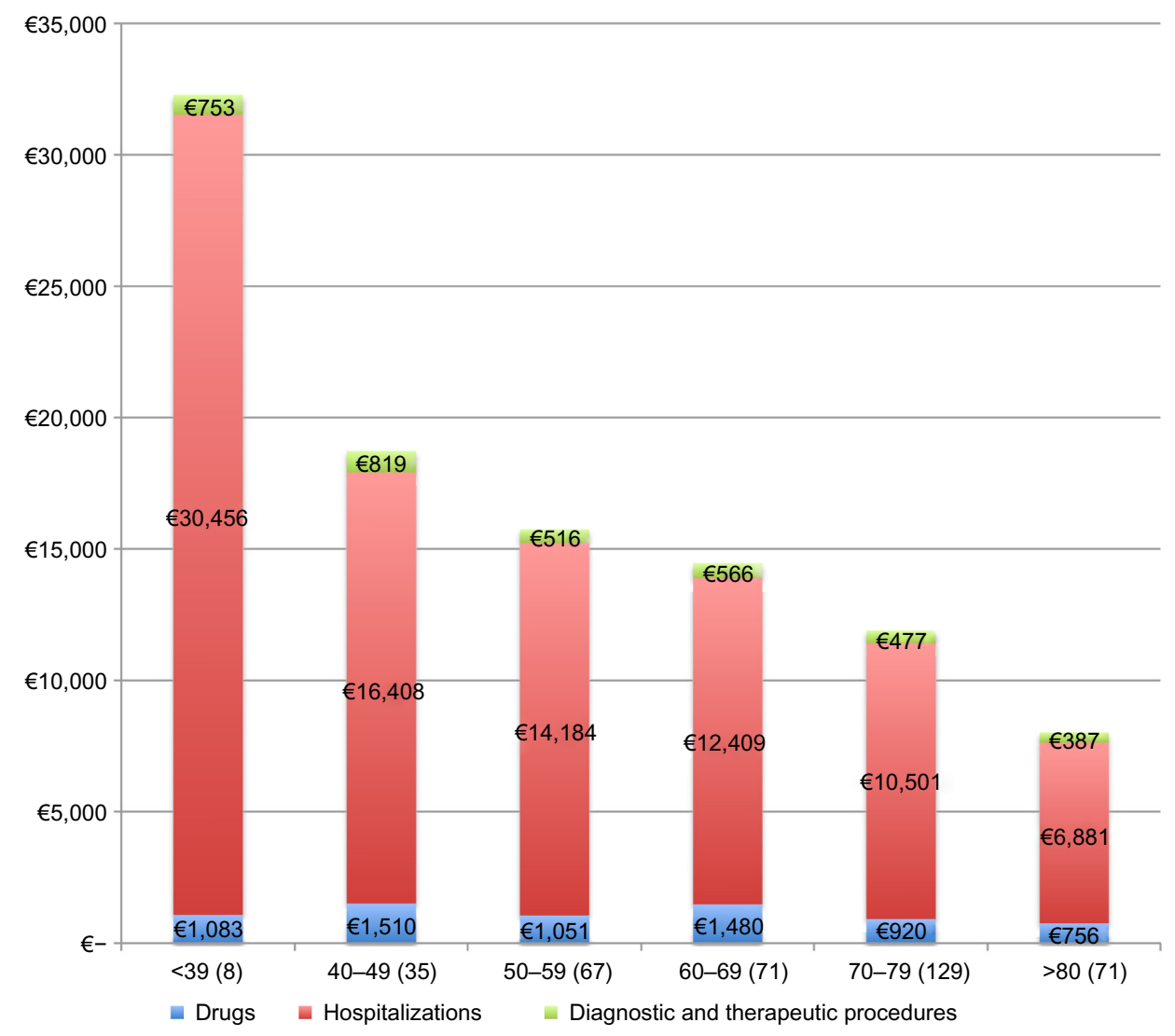

Figure I Average yearly cost per patient by age classes including index event $(n=38 I)$. 
Table 2 Average yearly cost per patient with and without recurrences

\begin{tabular}{lllll}
\hline & $\begin{array}{l}\text { Drugs } \\
(\text { mean } \pm \text { SD) }\end{array}$ & $\begin{array}{l}\text { Hospitalizations } \\
(\text { mean } \pm \text { SD) }\end{array}$ & $\begin{array}{l}\text { Diagnostic and therapeutic } \\
\text { procedures (mean } \pm \text { SD) }\end{array}$ & $\begin{array}{l}\text { Total } \\
(\text { mean } \pm \text { SD) }\end{array}$ \\
\hline Patient without recurrences $(n=172)$ & $€ 1,173 \pm 1,657$ & $€ 10,196 \pm 22,182$ & $€ 729 \pm 1,519$ & $€ 12,098 \pm 23,194$ \\
Patient with recurrences $(n=124)$ & $€ 1,633 \pm 1,807$ & $€ 18,970 \pm 16,652$ & $€ 669 \pm 974$ & $€ 21,272 \pm 17,587$ \\
\hline
\end{tabular}

Abbreviation: SD, standard deviation.

and complications related to HE progression and treatments (Table 3); the 20 most frequent diagnoses represented $69 \%$ of the total ordinary hospitalizations. With an average 35 days of hospital stay per patient during the follow-up period, the most frequent diagnoses that represent $>50 \%$ of total hospitalization days were strictly related to liver diseases (nonalcoholic hepatic cirrhosis, hepatic alcoholic cirrhosis, hepatic cancer, and hepatic coma).

Out of a total of 94 day-hospital admissions during the follow-up, the four most frequent diagnoses, which represented $30 \%$ of the total day hospitals, were strictly related to liver diseases (cirrhosis of liver without mention of alcohol, alcoholic cirrhosis of liver, primary malignant neoplasm of liver, and hepatic coma).

Most frequently prescribed drugs and average yearly expenditure per patient are reported in Table 4.

\section{Discussion}

This analysis of data deriving from a large Italian population highlights the relevance of the healthcare costs for the management of patients suffering from overt $\mathrm{HE}$ ( $€ 13,393 /$ patient/year [15,295 USD/patient/year]). The relevance of such analysis was also highlighted by the EASL Clinical Practice Guidelines in the section "Suggestions for

Table 3 Most frequent hospitalization causes during follow-up

\begin{tabular}{|c|c|c|c|c|c|c|}
\hline $\begin{array}{l}\text { ICD9-CM } \\
\text { code }\end{array}$ & Diagnosis & $\begin{array}{l}\text { Number of } \\
\text { hospitalized } \\
\text { patients }\end{array}$ & $\begin{array}{l}\text { Percentage of } \\
\text { hospitalized } \\
\text { patients (out of } \\
299 \text { patients) }\end{array}$ & $\begin{array}{l}\text { Total } \\
\text { number of } \\
\text { hospitalizations }\end{array}$ & $\begin{array}{l}\text { Average length } \\
\text { of stay (days } \\
\text { per hospitalized } \\
\text { patient) } \\
\text { (mean } \pm \text { SD) }\end{array}$ & $\begin{array}{l}\text { Mean expenditure } \\
\text { for hospitalizations } \\
\text { during follow-up (per } \\
\text { hospitalized patient) } \\
\text { (mean } \pm \text { SD) }\end{array}$ \\
\hline 571.5 & $\begin{array}{l}\text { Cirrhosis of liver without } \\
\text { mention of alcohol }\end{array}$ & 79 & $26.4 \%$ & 154 & $22.48 \pm \mid 9.51$ & $€ 8,929.38 \pm 13,746.17$ \\
\hline 572.2 & Hepatic coma & 55 & $18.4 \%$ & 97 & $|7.53 \pm 20.9|$ & $€ 6,7 \mid I .03 \pm 6,682.75$ \\
\hline 571.2 & Alcoholic cirrhosis of liver & 50 & $16.7 \%$ & 75 & $19.92 \pm 31.55$ & $€ 6,25 \mathrm{I} .19 \pm 5,013.35$ \\
\hline 155.0 & $\begin{array}{l}\text { Malignant neoplasm of liver, } \\
\text { primary }\end{array}$ & 24 & $8.0 \%$ & 30 & $15.00 \pm 10.36$ & $€ I I, 5 I 0.20 \pm 20,635.43$ \\
\hline 348.31 & Metabolic encephalopathy & 8 & $2.7 \%$ & 9 & $13.88 \pm 12.14$ & $€ 5,327.67 \pm 1,478.42$ \\
\hline 518.81 & Acute respiratory failure & 8 & $2.7 \%$ & 8 & $7.25 \pm 5.73$ & $€ 2,4 I 5.33 \pm 1,345.85$ \\
\hline 728.2 & $\begin{array}{l}\text { Muscular wasting and disuse } \\
\text { atrophy, not elsewhere classified }\end{array}$ & 8 & $2.7 \%$ & 8 & $29.00 \pm 15.68$ & $€ 4,368.00 \pm 2,445.34$ \\
\hline 572.4 & Hepatorenal syndrome & 7 & $2.3 \%$ & II & $23.00 \pm 11.24$ & $€ 5,616.3 \mathrm{I} \pm 2,700.86$ \\
\hline 428.0 & Heart failure & 5 & $1.7 \%$ & 5 & $23.60 \pm 11.82$ & $€ 4,566.15 \pm 2,461.88$ \\
\hline 485 & $\begin{array}{l}\text { Bronchopneumonia, organism } \\
\text { unspecified }\end{array}$ & 5 & $1.7 \%$ & 5 & $10.80 \pm 8.98$ & $€ 3,240.1 \mathrm{I} \pm 1,460.46$ \\
\hline 584.9 & Acute kidney failure, unspecified & 4 & $1.3 \%$ & 5 & $10.00 \pm 5.10$ & $€ 5,535.24 \pm 1,753.42$ \\
\hline 789.5 & Ascites & 4 & $1.3 \%$ & 8 & $16.25 \pm 8.22$ & $€ 6,324.74 \pm 5,023.70$ \\
\hline 008.45 & $\begin{array}{l}\text { Intestinal infection due to } \\
\text { Clostridium difficile }\end{array}$ & 3 & $1.0 \%$ & 3 & $12.33 \pm 0.67$ & $€ I, 708.00 \pm 1,479.17$ \\
\hline 038.42 & Septicemia due to Escherichia coli & 3 & $1.0 \%$ & 3 & $20.00 \pm 14.42$ & $€ 4,597.00$ \\
\hline 280.0 & $\begin{array}{l}\text { Iron deficiency anemia secondary } \\
\text { to blood loss (chronic) }\end{array}$ & 3 & $1.0 \%$ & 3 & $8.00 \pm 2.65$ & $€ 2,533.01 \pm 694.47$ \\
\hline 428.1 & Left ventricular failure & 3 & $1.0 \%$ & 4 & $16.33 \pm 18.01$ & $€ 3, \mid 172.73 \pm 2,860.48$ \\
\hline 511.9 & Unspecified pleural effusion & 3 & $1.0 \%$ & 4 & $27.33 \pm 21.55$ & $€ 6,528.8 \mathrm{I} \pm 5,254.34$ \\
\hline 567.23 & Spontaneous bacterial peritonitis & 3 & $1.0 \%$ & 3 & $12.00 \pm 1.73$ & $€ 2,394.36 \pm 574.15$ \\
\hline 572.3 & Portal hypertension & 3 & $1.0 \%$ & 3 & $8.00 \pm 5.29$ & $€ 5,624.87 \pm 6,595.14$ \\
\hline 573.8 & Disorder of liver, specified & 3 & $1.0 \%$ & 3 & $20.67 \pm 18.17$ & $€ 4,252.7 I \pm I, I I 7.60$ \\
\hline
\end{tabular}

Abbreviations: SD, standard deviation; ICD9-CM, International Classification of Diseases, Ninth Revision, Clinical Modification. 
Table 4 Most frequently prescribed drugs

\begin{tabular}{lllll}
\hline ATC & Description & $\begin{array}{l}\text { Number of } \\
\text { patients treated }\end{array}$ & $\begin{array}{l}\text { Percentage on total } \\
\text { patient population }(\mathbf{n}=\mathbf{3 8 I})\end{array}$ & $\begin{array}{l}\text { Mean per patient } \\
\text { expenditure }(\mathbf{n}=\mathbf{3 8 I}) \text { (mean) }\end{array}$ \\
\hline A02 & Drugs for acid-related disorders & 242 & $63.5 \%$ & $€ 82.1$ \\
C03 & Diuretics & 233 & $61.2 \%$ & $€ 53.0$ \\
A07 & Antidiarrheals, intestinal & 193 & $50.7 \%$ & $€ 136.2$ \\
& anti-inflammatory/anti-infective agents & & & $€ I I 5.5$ \\
A06 & Drugs for constipation & 186 & $48.8 \%$ & $€ 24.0$ \\
J01 & Antibacterials for systemic use & 160 & $42.0 \%$ & $€ 6.1$ \\
C07 & Beta-blocking agents & 129 & $33.9 \%$ & $€ 37.4$ \\
B01 & Blood and blood forming organs & 99 & $26.0 \%$ & $€ 77.9$ \\
A10 & Alimentary tract and metabolism & 94 & $24.7 \%$ & $€ I 3.2$ \\
B02 & Antihemorrhagics & 87 & $22.8 \%$ & $€ I 75.3$ \\
B05 & Blood substitutes and perfusion solutions & 85 & $22.3 \%$ & \\
\hline
\end{tabular}

Abbreviation: ATC, anatomical therapeutic chemical classification system.

future research in HE", which indicates the importance of economic studies in order to demonstrate the effects of HE on patients and society. ${ }^{15}$

The present analysis highlights also how the recurrence rate of overt $\mathrm{HE}$ episodes generates a high need of hospitalizations ( $42.5 \%$ of total patients with overt HE). The difference in annual costs, if we compare patients with and without HE episodes requiring hospitalization, is relevant (€12,098 [13,816 USD] vs €21,272 [24,293 USD], respectively). Moreover, the mortality rate linked to the considered disease is significant ( $28 \%$ including patients died both at index hospitalization and during follow-up). These data confirm those reported in the literature. ${ }^{11,16}$ As reported in the previously published studies, ${ }^{10,11}$ the costs of ordinary hospitalizations and day hospitals represent the most relevant cost driver for overt HE patients. A comparison between the results of the present analysis and those of other studies ${ }^{10,11}$ is not feasible, because healthcare services, settings, and coverages differ; however, the present study confirms the importance of the costs of hospitalizations and high mortality rates. A high readmission rate related to $\mathrm{HE}$ has been confirmed and is comparable to the results of other studies. ${ }^{17,18}$

Major limitation of the analysis of administrative databases is represented by the absence of single additional clinical information on in-hospital mortality rates and on the severity of the disease; furthermore, the impossibility of calculation of indirect costs ${ }^{19}$ could have a possible impact on the global economic burden of the disease..$^{20}$ Moreover, the costs reported in the analysis represent the real total direct healthcare costs in charge to INHS for the treatment of patients hospitalized for overt HE; a sharing of the costs related to $\mathrm{HE}$ and of those due to comorbidities or concomitant pathologies was not possible.
The relevant advantages deriving from the use of administrative databases are constituted by real-life data on treatment and procedures, with specific reference to costs of a large sample of patients in charge to INHS observed in a longitudinal way. The possibility offered by administrative databases to collect longitudinal data on each patient and to link individual records from different datasets make administrative databases as useful tools for those analyses focused on resource utilization and patterns of treatment and outcomes. ${ }^{21,22}$

\section{Conclusion}

The relevant direct healthcare costs of patients with overt HE and the high in-hospital mortality and rehospitalization rates highlighted in our study underline the importance of effective treatments and prevention of HE recurrences.

\section{Acknowledgments}

The authors are grateful to Silvia Fornoni for proofreading of the text. This study was supported by an unrestricted grant of Alfa Wassermann.

\section{Author contributions}

All authors conceived the study, performed the analysis, and have written the manuscript. All authors contributed toward drafting and revising the paper and agree to be accountable for all aspects of the work.

\section{Disclosure}

AR and DPR are consultants for Alfa Wassermann. ER, EC, and MDR declare no conflicts of interest for this work. AG is speaker's bureau for Janssen, Gilead, Alfa Wassermann, MSD, Zambon, BMS, and AbbVie. PMP was the clinical research director for Alfa Wassermann at the moment of 
the study. The authors report no other conflicts of interest in this work.

\section{References}

1. Vilstrup H, Amodio P, Bajaj J, et al. Hepatic encephalopathy in chronic liver disease: 2014 Practice Guideline by the European Association for the Study of the Liver and the American Association for the Study of Liver Diseases. Hepatology. 2014;60(2):715-735.

2. Bustamante J, Rimola A, Ventura PJ, et al. Prognostic significance of hepatic encephalopathy in patients with cirrhosis. J Hepatol. 1999;30: 890-895.

3. Arguedas MR, DeLawrence TG, McGuire BM. Influence of hepatic encephalopathy on health-related quality of life in patients with cirrhosis. Dig Dis Sci. 2003;48:1622-1626.

4. Younossi ZM, Boparai N. Assessment of utilities and health-related quality of life in patients with chronic liver disease. Am J Gastroenterol. 2001;96(2):579-583.

5. Groeneweg M, Quero JC, De Bruijn I, et al. Subclinical hepatic encephalopathy impairs daily functioning. Hepatology. 1998;28(1): 45-49.

6. Sanyal A, Younossi ZM, Bass NM, et al. Randomised clinical trial: rifaximin improves health-related quality of life in cirrhotic patients with hepatic encephalopathy - a double-blind placebo-controlled study. Aliment Pharmacol Ther. 2011;34(8):853-861.

7. Bass NM, Mullen KD, Sanyal A, et al. Rifaximin treatment in hepatic encephalopathy. N Engl J Med. 2010;362(12):1071-1078.

8. The Burden of Gastrointestinal Diseases. Bethesda, Maryland: American Gastroenterological Association; 2001:41-42.

9. The Multidimensional Burden of Hepatic Encephalopathy. Chronic Liver Disease Foundation. Available from: http://www.chronicliverdisease.org/ disease_focus/enewsletters/HepCoEE_eNewsLetter_Multidimensional_ burden.pdf. Accessed May 21, 2015

10. Leevy CB. Economic impact of treatment options for hepatic encephalopathy. Semin Liver Dis. 2007;27(Suppl 2):26-31.

11. Stepanova M, Mishra A, Venkatesan C, Younossi ZM. In-hospital mortality and economic burden associated with hepatic encephalopathy in the United States from 2005 to 2009. Clin Gastroenterol Hepatol. 2012;10(9):1034.e-1041.e.
12. ARNO Osservatorio [database on the Internet]. CINECA. Available from: http://osservatorioarno.cineca.org. Accessed May 21, 2015. [Italian language].

13. International Classification of Diseases (ICD): 9th Revision, Basic Tabulation List with Alphabetic Index. Geneva: World Health Organization; 1978.

14. Charlson ME, Pompei P, Ales KL, MacKenzie CR. A new method of classifying prognostic comorbidity in longitudinal studies: development and validation. J Chronic Dis. 1987;40:373-383.

15. European Association for the Study of the Liver. Hepatic Encephalopathy in Chronic Liver Disease: 2014. Suggestions for Future Research. Available from: http://www.easl.eu/research/our-contributions/clinicalpractice-guidelines/detail/hepatic-encephalopathy-in-chronic-liverdisease-2014/report/9. Accessed May 21, 2015.

16. Morgan CL, Jenkins-Jones S, Radwan A, et al. Mortality associated with hepatic encephalopathy in patients with severe liver disease. Gut. 2014;63:A94. [Poster presentations PTU-126].

17. Volk ML, Tocco RS, Bazick J, Rakoski MO, Lok AS. Hospital readmissions among patients with decompensated cirrhosis. Am J Gastroenterol. 2012;107(2):247-252.

18. Orr J, Morgan CL, Hudson M, et al. Resource use associated with hepatic encephalopathy in patients with severe liver disease. Gut. 2014;63:A94-A95.

19. Haut ER, Pronovost PJ, Schneider EB. Limitations of administrative databases. JAMA. 2012;307(24):2589-2590.

20. Bajaj JS, Wade JB, Gibson DP, et al. The multi-dimensional burden of cirrhosis and hepatic encephalopathy on patients and caregivers. Am J Gastroenterol. 2011;106:1646-1653.

21. Schneeweiss S, Avorn J. A review of uses of healthcare utilization databases for epidemiologic research on therapeutics. JClin Epidemiol. 2005;58(4):323-337.

22. Harpe SE. Using secondary data sources for pharmacoepidemiology and outcomes research. Pharmacotherapy. 2009;29(2):138-153.
Hepatic Medicine: Evidence and Research

\section{Publish your work in this journal}

Hepatic Medicine: Evidence and Research is an international, peerreviewed, open access journal covering all aspects of adult and pediatric hepatology in the clinic and laboratory including the following topics: Pathology, pathophysiology of hepatic disease; Investigation and treatment of hepatic disease; Pharmacology of drugs used for

\section{Dovepress}

the treatment of hepatic disease. Issues of patient safety and quality of care will also be considered. The manuscript management system is completely online and includes a very quick and fair peer-review system, which is all easy to use. Visit http://www.dovepress.com/ testimonials.php to read real quotes from published authors. 